\title{
Autoaprendizaje guiado: Un Ciclo de Mejora en el Aula de Proyectos I de Arquitectura
}

\section{Guided Self-Learning: An Improvement Cycle in Classroom of Desing I in Architecture}

CRISTINA VICENTE GILABERT

https://orcid.org/0000-0001-8309-0352

Universidad de Sevilla

Departamento de Proyectos Arquitectónicos

cvicente@us.es

DOI: http://dx.doi.org/10.12795/9788447231003.071

Рр.: 1509-1530 


\section{Contexto}

El Ciclo de Mejora en el Aula (CIMA) que se desarrolla en este capítulo, ha sido aplicado en la primera de las diez asignaturas de Proyectos que cursan los alumnos y alumnas del Grado en Fundamentos de la Arquitectura, por lo que supone su primer acercamiento al proceso creativo del proyecto arquitectónico.

En esta asignatura, los estudiantes, recién llegados de bachillerato, se enfrentan por primera vez a trabajar con conceptos abstractos como la luz o el espacio, que se alejan de las formalidades cotidianas. Por primera vez se enfrentan, también, a trabajar con referencias arquitectónicas y artísticas complejas que requieren un desarrollo del carácter crítico, y a emplear un lenguaje que hasta el momento apenas conocen: la expresión gráfica arquitectónica.

Por lo tanto, reconocer las experiencias del espacio, aplicarlas en un proyecto y comunicarlas gráficamente de manera correcta serán las principales competencias que deberán desarrollar durante este primer curso de Proyectos.

En este grupo concreto en el que se ha aplicado el CIMA, la asignatura se organiza en torno a cuatro ejercicios o proyectos, planteados a los alumnos como encargos de arquitectura que deben resolver respondiendo a diferentes programas, situaciones espaciales y requerimientos materiales, siendo progresivo el aumento de complejidad en cada uno de ellos. En dicho marco, el CIMA se aplicó durante el desarrollo del segundo de los ejercicios.

Otro dato que cabe reseñar es el modo de trabajo habitual de la asignatura, conforme al cuál las cuatro horas semanales de docencia se imparten en una sola sesión,

Ciclos de Mejora en el Aula (2020). Experiencias de Innovación Docente de la US Esta obra se distribuye con la licencia Creative Commons 
que tiene lugar los viernes por la tarde. Durante la semana los estudiantes trabajan el proyecto en casa, y al final de la misma lo ponen en común en clase, momento en que reciben las críticas de los profesores, con las que reelaboran de nuevo el material para la semana siguiente. De este modo la asignatura se evalúa mediante un proceso de evaluación continua, valorando los portafolios aportados por los alumnos al término de cada proyecto.

Para el diseño, aplicación y evaluación del CIMA se ha tomado una muestra de 17 alumnos de los 23 matriculados en la asignatura, siendo dos los profesores en el aula. Por motivos de la pandemia del COVID-19, la modalidad de las clases en que se desarrolló el CIMA fue virtual, empleando la herramienta provista por la Universidad de Sevilla Blackboard Collaborate Ultra.

\section{Diseño previo del CIMA}

\section{Mapa de contenidos}

Los contenidos abordados en el CIMA, que podrían extenderse a los de la asignatura completa, quedan recogidos en el siguiente mapa de contenidos, en el que se destacan en negro los esenciales: reconocer la experiencia del espacio, aplicarlos en el proyecto de arquitectura y comunicarlo gráficamente. Asimismo, se han incluido como esenciales la capacidad de analizar otros proyectos, y el desarrollo de la capacidad crítica y autocrítica, así como el rigor como principio fundamental. Los contenidos agrupados con la línea discontinua son los que dan lugar al producto: el proyecto finalizado

Como se puede observar en la leyenda, se han planteado cuatro tipos de contenidos: las ideas, entendiendo

Ciclos de Mejora en el Aula (2020). Experiencias de Innovación Docente de la US Esta obra se distribuye con la licencia Creative Commons 
que es información que se debe aprehender mediante la comprensión (referencias y conceptos abstractos); los procedimientos intelectuales; los procedimientos instrumentales, que tienen un carácter psicomotriz y se han relacionado directamente con el control de las técnicas de comunicación gráfica; y por último los valores asociados tanto a la profesión del arquitecto (rigor) como al trabajo en la asignatura (aceptar críticas, seguridad en uno mismo, respeto a las ideas de los demás, etc.)

Algo muy importante en el diseño del mapa de contenidos ha sido la distinción de dos tipos de relaciones, distinguiendo con una línea continua los contenidos que tienen relaciones directas, y con línea de puntos los que tienen una relación indirecta, esto es, que tienen una influencia en otros aunque no sea de una forma explícita. Así, por ejemplo, saber analizar otros proyectos no se materializa de forma tangible en el ejercicio en desarrollo, pero sí tiene una influencia en él puesto que ayuda a madurar conceptos, extrapolar soluciones espaciales, etc.

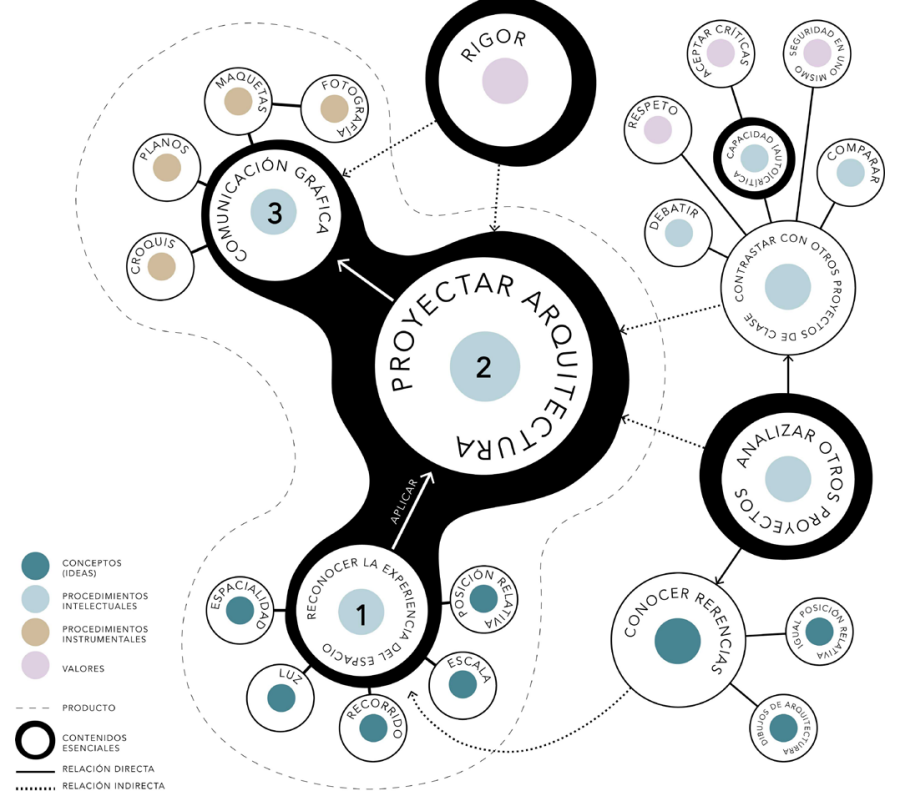

Figura 1. Mapa de contenidos Ciclos de Mejora en el Aula (2020). Experiencias de Innovación Docente de la US
Esta obra se distribuye con la licencia Creative Commons Reconocimiento-NoComercial-SinObraDerivada 


\section{Modelo metodológico posible y secuencias de actividades}

Como se ha introducido en el apartado del contexto, la aplicación del CIMA tuvo lugar en el momento central del desarrollo del segundo ejercicio del curso. En la figura 2 se puede observar el calendario de sesiones del ejercicio, en el que se han coloreado aquellas en las que tuvieron lugar las actividades del CIMA.

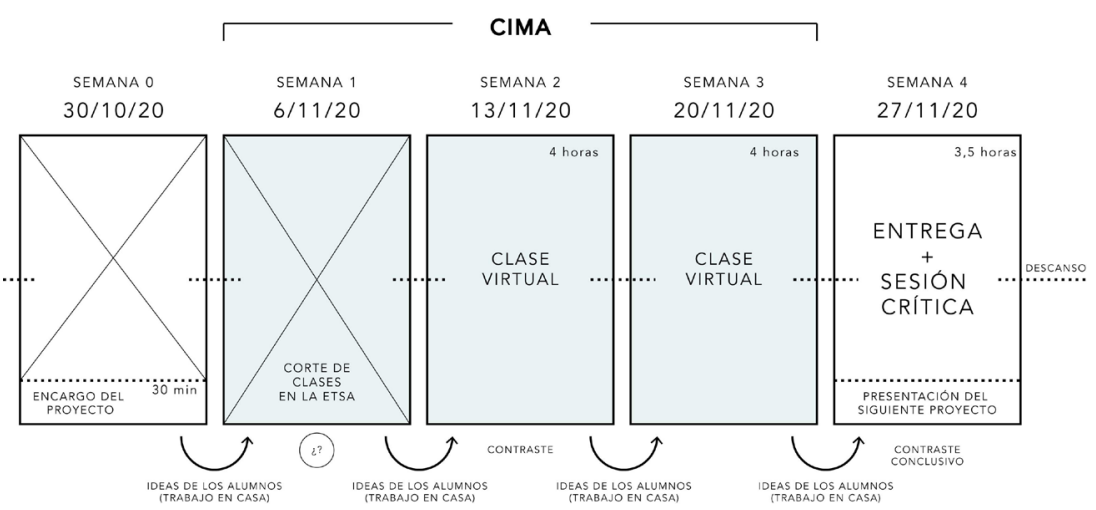

Figura 2. Ubicación temporal del CIMA en el proyecto en desarrollo. Cronograma de sesiones

El ejercicio en desarrollo, presentado en la que hemos llamado "semana 0" (previa al CIMA), consistía en diseñar un espacio pensado para comer en el paisaje desértico de la estepa rusa, incorporando una parte del programa en un espacio excavado bajo tierra y otra parte en una zona construida sobre ella; forzando así el trabajo con la línea del horizonte. Con este ejercicio, los alumnos debían abordar la definición de un programa, una idea espacial y de ocupación del territorio, el diseño de los recorridos, la resolución de la iluminación natural, así como la comunicación gráfica de sus ideas mediante maquetas, planos y otros materiales de libre elección.

Ciclos de Mejora en el Aula (2020). Experiencias de Innovación Docente de la US Esta obra se distribuye con la licencia Creative Commons 
A continuación se presenta el modelo metodológico posible, que se basa en una lógica de funcionamiento en bucle de "ideas de los alumnos" - "contraste". Es decir, los alumnos trabajan en casa sus propuestas y al llevarlas a clase se realizan las actividades de contraste que tratan de poner en juicio sus ideas mediante la puesta en común, en las tradicionalmente llamadas "correcciones", y también mediante un apoyo conceptual basado en el aporte de referencias, a lo que se suman otras actividades que tratan de motivar al alumno a que continúe trabajando los conceptos en casa.

Como se puede comprobar, tanto el modelo metodológico como las actividades propuestas se basan en el principio de que el aprendizaje del alumno es autónomo, siendo el papel del profesor el de diseñar estratégicamente las actividades que tratan de guiar su proceso de aprendizaje, mediante el aporte de información adicional o la realización de actividades de contraste, en este caso basadas en la observación de ejercicios de compañeros, la crítica o el debate. El modelo trata de alejarse del tradicional, que consiste en dar las soluciones directas, limitándose el alumno a reproducirlas sin comprender en muchas ocasiones realmente la razón por la que lo que hace.

Ciclos de Mejora en el Aula (2020). Experiencias de Innovación Docente de la US Esta obra se distribuye con la licencia Creative Commons 


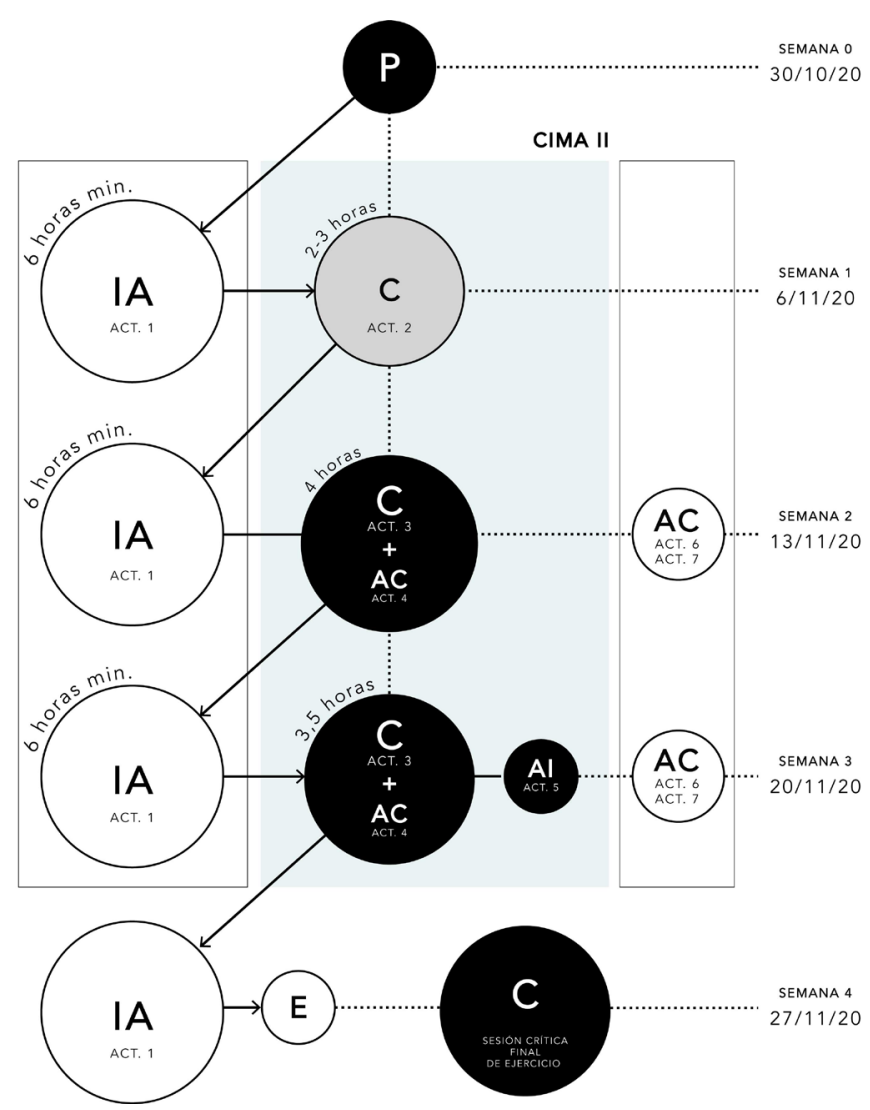

Figura 3. Modelo metodológico posible

Este modelo se complementa con el desarrollo de la siguiente tabla donde se describe en profundidad en qué consisten cada una de las actividades:

Ciclos de Mejora en el Aula (2020). Experiencias de Innovación Docente de la US (c) (i) $\odot-$ Esta obra se distribuye con la licencia Creative Commons 


\begin{tabular}{|c|c|c|c|}
\hline ACT. & NOMBRE & FASE & DURACIÓN \\
\hline 1 & $\begin{array}{l}\text { TRABAJO DEL PROYECTO } \\
\text { EN CASA }\end{array}$ & $\begin{array}{l}\text { IDEAS DE LOS } \\
\text { ALUMNOS (IA) }\end{array}$ & 6 horas mínimo \\
\hline \multicolumn{4}{|c|}{$\begin{array}{l}\text { Descripción: } \\
\text { Trabajo en casa sobre el proyecto planteado. }\end{array}$} \\
\hline \multicolumn{4}{|c|}{$\begin{array}{l}\text { Recursos: } \\
\text { Elaboración de maqueta y planos para presentar en la siguiente crítica o } \\
\text { corrección. }\end{array}$} \\
\hline ACT & NOMBRE & FASE & DURACIÓN \\
\hline 2 & CRÍTICAS CRUZADAS & CONTRASTE (C) & 2-3 horas \\
\hline \multicolumn{4}{|c|}{$\begin{array}{l}\text { Descripción: } \\
\text { Debido a la ausencia de clases en la que se debería desarrollar la actividad } \\
\text { de contraste, se ha propuesto la realización de un ejercicio de contraste entre } \\
\text { los propios alumnos. Para ello deberán presentarse por parejas el desarrollo } \\
\text { de los proyectos y ejercer de forma alterna los roles de crítico y criticado. } \\
\text { Dado que los alumnos son de primer curso y carecen de suficientes } \\
\text { conocimientos para elaborar una crítica, se les aporta un documento con } \\
\text { el enunciado y una "guía práctica del crítico", donde se plantean preguntas } \\
\text { agrupadas por conceptos para que sean tratados en el debate crítico que se } \\
\text { genera entre los alumnos. } \\
\text { El objetivo es no sólo que tengan que afrontar el análisis y evaluación } \\
\text { de un proyecto ajeno al suyo para ayudar a su compañero, sino hacerles } \\
\text { conscientes de esas críticas para que las aporten a su propio proyecto. } \\
\text { Al finalizar la actividad los alumnos deberán completar un cuestionario } \\
\text { planteado de forma que para contestar a las preguntas reflexionen sobre los } \\
\text { aspectos tratados. } \\
\text { Esta actividad se plantea con el objetivo de ofrecer una herramienta para } \\
\text { desarrollar el trabajo autónomo que les permita no ser dependientes de los } \\
\text { profesores. }\end{array}$} \\
\hline \multicolumn{4}{|c|}{$\begin{array}{l}\text { Recursos } \\
\text { - Enunciado con pautas y "Guía práctica del crítico" } \\
\text { - Cuestionario de reflexión (entrega obligatoria) }\end{array}$} \\
\hline ACT & NOMBRE & FASE & \\
\hline 3 & CORRECCIONES PÚBLICAS & & \\
\hline
\end{tabular}

Ciclos de Mejora en el Aula (2020). Experiencias de Innovación Docente de la US Esta obra se distribuye con la licencia Creative Commons Reconocimiento-NoComercial-SinObraDerivada $\quad 4.0$ Internacional (CC BY-NC-ND 4.0.) 


\section{Descripción:}

1. En una situación normal e ideal: colocación de las mesas juntas en el centro de la clase formando una gran mesa central. Los alumnos se sientan alrededor y colocan sus maquetas y planos sobre la mesa. Como es virtual, este paso se suprime y se sustituye por pedir a los alumnos que suban sus PDF a la plataforma para que todos puedan verlo. En las presentaciones deberán activar cámara y micrófono.

2. Cada alumno expone su trabajo y recibe una crítica constructiva de los profesores que tendrá el objetivo de hacer ver a los alumnos dónde están errando y por dónde continuar. Indicaciones para las críticas: se tratará de guiar mediante la formulación de preguntas de carácter abierto, tratando de no dar la solución que se considera "correcta" para que sea el propio alumno el que llegue a la conclusión más acertada. Además, se intentará implicar a los demás compañeros en la corrección, realizando también preguntas de opinión.

3. En las correcciones se prestará especial atención al trabajo con el reconocimiento del espacio: la luz, el espacio, la posición relativa con respecto al horizonte, y recorridos (ver mapa de contenidos). Además, se harán comentarios sobre la representación gráfica.

4. Finalmente, se apuntarán conceptos que sea necesario resaltar o no hayan quedado suficientemente claros.

\section{Recursos:}

Se trabaja con el material gráfico traído por los alumnos trabajado durante la semana previa a la sesión.

\section{Periodicidad:}

Se realizan todas las semanas, excepto las de finalización del ejercicio que se sustituyen por "sesiones críticas"; similares pero con un carácter más finalista.

\begin{tabular}{|c|c|c|c|}
\hline ACT & \multicolumn{1}{c}{ NOMBRE } & FASE & DURACIÓN \\
\hline $\mathbf{4}$ & $\begin{array}{c}\text { REFERENCIAS } \\
\text { SALPICADAS }\end{array}$ & $\begin{array}{c}\text { APOYO } \\
\text { CONCEPTUAL (AC) }\end{array}$ & $3,5-4$ horas \\
\hline
\end{tabular}

Ciclos de Mejora en el Aula (2020). Experiencias de Innovación Docente de la US Esta obra se distribuye con la licencia Creative Commons 


\section{Descripción:}

Como apoyo a los conceptos trabajados en el proyecto, y aprovechando los recursos del soporte digital en que se imparte la clase, se tendrán preparadas imágenes sobre referencias que se prevé que van a ser útiles (ya que se conocen las deficiencias de partida), y se irán incorporando a cada crítica para vislumbrar ideas en los alumnos. Se trata de sustituir una clase teórica en la que el profesor habla y los alumnos escuchan, por un apoyo conceptual dirigido y orientado a cada proyecto en particular, ayudando así a que los alumnos comprendan y hagan propias estas ideas por similitud con las que ellos mismos trabajan.

En las referencias elegidas se prestará una especial atención a los conceptos relacionados con el reconocimiento del espacio (contemplados en el mapa de contenidos), y se incluirán contenidos sobre representación gráfica empleada por los arquitectos de prestigio seleccionados.

Se ha llamado a la actividad "referencias salpicadas" porque no pretende concentrar en un mismo momento el discurso sobre las referencias, sino que se irán incorporando de forma puntual en cada exposición de cada alumno.

\section{Recursos:}

Aprovechando la situación de docencia virtual se incorporarán a la sesión las imágenes previamente seleccionadas (o que surjan en el momento de forma improvisada) como documentos compartidos, añadiendo en el chat los datos de referencia.

\begin{tabular}{|c|c|c|c|}
\hline ACT & \multicolumn{1}{c}{ NOMBRE } & FASE & DURACIÓN \\
\hline $\mathbf{5}$ & $\begin{array}{c}\text { FOTOGRAFíA DE } \\
\text { MAQUETAS }\end{array}$ & $\begin{array}{c}\text { APOYO } \\
\text { INSTRUMENTAL (AI) }\end{array}$ & 30 minutos \\
\hline
\end{tabular}

\section{Descripción:}

Dado que se ha detectado, tras el análisis del trabajo previo, que existe una gran deficiencia en la forma de abordar la fotografía de las maquetas (tanto técnica como conceptualmente), se propone dedicar el final de la clase previa a la entrega a abordar este contenido.

La actividad consistirá en una presentación en la que se explique cómo diseñar estratégicamente las fotografías que se van a realizar (luz, orientación, qué partes interesa contar, perspectivas, etc.) y cómo componerlas para que la calidad gráfica de las mismas sea adecuada.

La idea es conseguir que una persona externa a la asignatura, dedicada profesionalmente a la fotografía de arquitectura, participe en esta sesión. No obstante, si finalmente esta persona no pudiera hacerlo, la abordarían los profesores.

\section{Recursos:}

Presentación de diapositivas.

\begin{tabular}{|c|c|c|c|}
\hline ACT & NOMBRE & FASE & DURACIÓN \\
\hline 6 & LECTURA DE LA SEMANA & $\begin{array}{c}\text { APOYO } \\
\text { CONCEPTUAL (AC) }\end{array}$ & Libre \\
\hline
\end{tabular}

Ciclos de Mejora en el Aula (2020). Experiencias de Innovación Docente de la US Esta obra se distribuye con la licencia Creative Commons Reconocimiento-NoComercial-SinObraDerivada $\quad 4.0$ Internacional (CC BY-NC-ND 4.0.) 


\section{Descripción:}

Con el objetivo de dar las pautas a los alumnos para que continúen su formación en casa, se decidió a inicios del curso que cada semana se entregara una "hoja de la semana" en la que se incluyera un fragmento de lectura, así como referencias o cualquier otro material complementario que refuerce los conceptos trabajados en clase. La idea es que los alumnos lo lean en casa y reflexionen para aplicarlas a su proyecto.

Estas hojas se plantean como un "coleccionable" al que siempre podrán recurrir durante su formación en el grado y vida profesional futura.

(Nota: Esta actividad no se ha diseñado específicamente para el CIMA, sino que se comenzó a realizar desde el inicio del curso y cada semana se entrega una nueva)

\section{Recursos:}

Hoja de la semana entregada en clase.

\begin{tabular}{|c|c|c|c|}
\hline ACT & \multicolumn{1}{|c}{ NOMBRE } & FASE & DURACIÓN \\
\hline 7 & $\begin{array}{c}\text { ARQUITECTO/A DE LA } \\
\text { SEMANA }\end{array}$ & $\begin{array}{c}\text { APOYO } \\
\text { CONCEPTUAL (AC) }\end{array}$ & Libre \\
\hline
\end{tabular}

\section{Descripción:}

Continuando con el objetivo de dar las pautas a los alumnos para que continúen su formación autónoma en casa, cada semana se plantea a los alumnos el reto de investigar a un arquitecto que "les acompañará durante la semana".

Este arquitecto es seleccionado previamente por los profesores entre los que presenten un interés especial en el tratamiento de los conceptos clave del proyecto planteado.

(Nota: Esta actividad no se ha diseñado específicamente parra el CIMA, sino que se comenzó a realizar desde el inicio del curso y cada semana se propone uno nuevo)

\section{Recursos:}

Los alumnos recogerán las investigaciones llevadas a cabo en su cuaderno personal, que se evaluará al final del curso.

\section{Clasificación de los niveles de progresión en el aprendizaje}

Para realizar el seguimiento de la evolución de los estudiantes en relación con los contenidos esenciales, el cuestionario que se suele emplear en estos casos se sustituye por un cuadro de clasificación de los niveles de progresión en el aprendizaje. Esto se debe a que la asignatura tiene un carácter gráfico y una necesidad de desarrollo del

Ciclos de Mejora en el Aula (2020). Experiencias de Innovación Docente de la US Esta obra se distribuye con la licencia Creative Commons 
trabajo en el tiempo, que no podría responderse por escrito en un tiempo breve. Por este motivo se tomará como referencia inicial el portafolio del primer proyecto entregado por los alumnos, y como referencia final el entregado para el segundo proyecto (desarrollado durante el CIMA).

En la tabla siguiente se han recogido a la izquierda los contenidos que se evalúan, y a la derecha los niveles a los que se encuentran los modelos mentales de los alumnos con respecto a los contenidos, siendo el nivel A el más elevado, correspondiente al nivel máximo esperado, B el intermedio, y C el nivel más bajo.

Cabe aclarar que dado que la asignatura pretende la adquisición de competencias de forma continuada, el nivel máximo es el esperado al final del curso, y no necesariamente al final del CIMA.

Tabla 2. Clasificación de los niveles de progresión en el aprendizaje

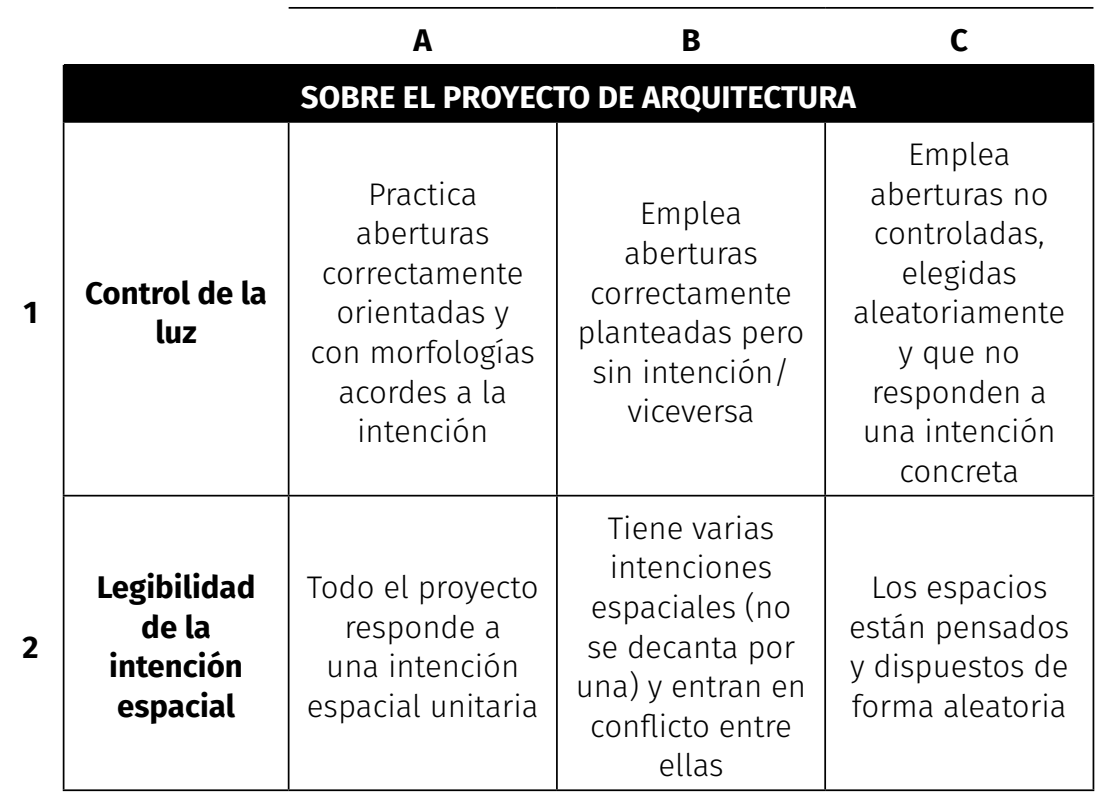

Ciclos de Mejora en el Aula (2020). Experiencias de Innovación Docente de la US Esta obra se distribuye con la licencia Creative Commons 
3

4

5

6

\section{escala en los espacios}

Control de la en la

asignación de

superficies
El proyecto

tiene un interés

espacial en tres

dimensiones

Lo excavado

es puramente

excavado, y

lo construido

puramente

construido

Emplea

transiciones

espaciales

cuidando la

escala y la

visibilidad

El proyecto

tiene un interés

espacial en dos

dimensiones

(planta o

sección)

En ocasiones

se mezclan

elementos

excavados y

construidos

Emplea

geometrías

imposibles

Las transiciones

entre los

espacios

responden a

lo requerido

pero son muy estándar

Asignación

coherente con

su intención

su intención

espacial.

Equilibrado

aunque existen

espacios

desequilibrados

Existe un control

aunque pero

no se generan

suficientes

tensiones

entre espacios

distintos

claridad

\section{Espacios}

excavados y

construidos

planteados sin

No presta atención a las

transiciones

entre espacios

Asigna

superficies que

no responden a

una coherencia

con sus propias intenciones

No reflexiona

sobre la escala

corpórea del

espacio

\section{SOBRE LA EXPRESIÓN GRÁFICA DEL PROYECTO}

\begin{tabular}{|c|c|c|c|}
\hline $\begin{array}{l}\text { Coherencia } \\
\text { en el discurso } \\
\text { gráfico }\end{array}$ & $\begin{array}{l}\text { Orden lógico, } \\
\text { rotulaciones } \\
\text { correctas y } \\
\text { selección de } \\
\text { dibujos precisa }\end{array}$ & $\begin{array}{c}\text { Orden lógico } \\
\text { pero emplea } \\
\text { dibujos } \\
\text { innecesarios y } \\
\text { omite otros que } \\
\text { sí lo serían }\end{array}$ & $\begin{array}{l}\text { Presenta } \\
\text { formatos con un } \\
\text { orden aleatorio } \\
\text { que no responde } \\
\text { a un discurso } \\
\text { gráfico específico }\end{array}$ \\
\hline
\end{tabular}

Ciclos de Mejora en el Aula (2020). Experiencias de Innovación Docente de la US Esta obra se distribuye con la licencia Creative Commons 


\begin{tabular}{|c|c|c|c|}
\hline Planos & $\begin{array}{l}\text { Son correctos } \\
\text { tanto el } \\
\text { planteamiento } \\
\text { como la } \\
\text { ejecución }\end{array}$ & $\begin{array}{l}\text { Se entienden } \\
\text { aunque hay } \\
\text { errores de } \\
\text { ejecución y/o } \\
\text { elementos poco } \\
\text { definidos }\end{array}$ & $\begin{array}{c}\text { Presentan } \\
\text { grandes errores } \\
\text { de ejecución y } \\
\text { conceptuales. No } \\
\text { se entienden o } \\
\text { no responden a } \\
\text { la realidad }\end{array}$ \\
\hline Maqueta & $\begin{array}{l}\text { Es posible } \\
\text { comprender el } \\
\text { espacio con la } \\
\text { maqueta y está } \\
\text { bien ejecutada }\end{array}$ & $\begin{array}{c}\text { Es posible } \\
\text { comprender } \\
\text { bien el espacio } \\
\text { aunque hay } \\
\text { errores de } \\
\text { ejecución }\end{array}$ & $\begin{array}{c}\text { Planteamiento } \\
\text { y/o ejecución } \\
\text { completamente } \\
\text { deficientes. } \\
\text { No es posible } \\
\text { comprenderla }\end{array}$ \\
\hline Fotografía & $\begin{array}{c}\text { Intención clara, } \\
\text { buena ejecución } \\
\text { cuidando la luz, } \\
\text { el enfoque y el } \\
\text { fondo }\end{array}$ & $\begin{array}{l}\text { Intención clara } \\
\text { pero mala } \\
\text { ejecución, pues } \\
\text { no cuida la luz, } \\
\text { el enfoque y el } \\
\text { fondo }\end{array}$ & $\begin{array}{c}\text { No existe una } \\
\text { intención clara } \\
\text { y la foto está } \\
\text { descuidada }\end{array}$ \\
\hline $\begin{array}{l}\text { Cuidado de la } \\
\text { presentación }\end{array}$ & $\begin{array}{l}\text { Presentación } \\
\text { limpia, ordenada, } \\
\text { cuidando las } \\
\text { rotulaciones } \\
\text { y con unidad } \\
\text { de estilo, } \\
\text { empleando } \\
\text { imágenes con } \\
\text { calidad }\end{array}$ & $\begin{array}{c}\text { Presentación } \\
\text { ordenada, con } \\
\text { unidad de estilo. } \\
\text { Mala calidad en } \\
\text { las imágenes } \\
\text { empleadas }\end{array}$ & $\begin{array}{c}\text { Presentación } \\
\text { desordenada, sin } \\
\text { unidad de estilo } \\
\text { y empleando } \\
\text { imágenes sin } \\
\text { calidad }\end{array}$ \\
\hline
\end{tabular}

\section{Aplicación del CIMA}

\section{Diario de sesiones}

\section{SESIÓN 1 (semana 1):}

La primera sesión no corresponde a una clase en sí sino a una actividad que los alumnos debían realizar de forma autónoma, sirviéndose de un material con pautas para llevar a cabo el ejercicio. Para realizar un control de

Ciclos de Mejora en el Aula (2020). Experiencias de Innovación Docente de la US Esta obra se distribuye con la licencia Creative Commons 
la realización de la actividad, tras realizarla, los alumnos contestaron un cuestionario en el que respondían a preguntas sobre su experiencia como crítico y su experiencia como criticado; algunas relacionadas con las sensaciones y otras con los contenidos de los proyectos. La actividad tuvo una participación de 21/23 alumnos, y en general una acogida bastante positiva, ya que el carácter crítico no se suele trabajar de forma específica en esta asignatura, y los alumnos lo han agradecido. Algunos comentarios que lo corroboran, recogidos del cuestionario, son los siguientes:

"Ha sido útil ya que hemos podido dialogar sobre nuestros proyectos y darnos cuenta realmente de fallos que estábamos cometiendo gracias a nuestras críticas. Además es un gran apoyo saber que tu compañero también tiene sus problemas al realizar al actividad."

"Creo que va a ser útil tanto para este proyecto como para todo en general, ya que es un inicio en la mentalidad crítica y saber opinar."

"Me he sentido más cómoda en el rol de crítico, ya que a la vez que le iba comentando algunas cosas sobre su proyecto me iba dado cuenta de otras que yo debía mejorar o tener en cuenta."

"No estaba del todo segura con lo que estaba haciendo y tampoco sabía por donde tirar o seguir investigando, después de las críticas constructivas tanto de ella como mías tengo un par de ideas para seguir investigando y probando."

"Aunque las dos nos lo hemos planteado de una forma totalmente distinta, los requisitos que tenemos que cumplir con los mismos, por lo que puedes ver como con un enunciado pueden surgir ideas muy diferentes."

Ciclos de Mejora en el Aula (2020). Experiencias de Innovación Docente de la US Esta obra se distribuye con la licencia Creative Commons 
"Considero que ha sido útil porque asi tienes más de un punto de vista de un mismo proyecto y de este modo te replanteas ciertos aspectos del tuyo y podéis compartir alguna idea. Además, el hecho de criticar otro proyecto hace que te des cuenta de las cosas que fallan en el tuyo y que también aprendas a ser más crítico contigo mismo."

SESIÓN 2 (semana 2):

Después de dos semanas sin clase, tuvimos la primera puesta en común del ejercicio, esta vez de forma virtual. La actividad realizada fue la 3 (correcciones públicas) y 4 (referencias salpicadas). Realmente los alumnos traían bastante material para trabajar, y además se mostraron participativos compartiendo sus maquetas a través de la cámara y sus presentaciones con los dibujos escaneados.

La dinámica de la clase consistió en que los alumnos explicaban, y después los profesores interveníamos. Mis intervenciones se centraron principalmente en las referencias salpicadas, compartiendo con los alumnos la información gráfica previamente seleccionada, y comentando algunas similitudes que podrían tener con sus proyectos. La impresión fue que los alumnos agradecieron bastante ver en pantalla las referencias gráficas y comentarlas, ya que en la clase presencial esto no es posible. Considero que fue más claro para los alumnos ver las referencias en relación a sus propios proyectos, que el modelo tradicional de una clase teórica en el que se muestra la misma información desvinculada de sus trabajos.

SESIÓN 3 (semana 3):

La sesión 3 se desarrolló de un modo muy similar a la sesión 2, si bien no se pudo realizar la actividad prevista sobre apoyo instrumental por falta de tiempo. No obstante se introdujeron comentarios y ejemplos sobre aspectos gráficos en sus presentaciones, haciendo especial incidencia en la fotografía de maquetas y los planos, donde se habían detectado las mayores dificultades.

Ciclos de Mejora en el Aula (2020). Experiencias de Innovación Docente de la US Esta obra se distribuye con la licencia Creative Commons 


\section{Evaluación del aprendizaje de los estudiantes}

La evolución del aprendizaje de los estudiantes se ha evaluado mediante el método gráfico de las Escaleras de Aprendizaje y el Cuadro de Evolución Individual. A continuación se muestra, a modo de ejemplo, algunas de las escaleras generadas, en las que se detallado los obstáculos que se deben superar para ascender en ella, así como la estadística de alumnos que se encontraban en cada nivel en el momento inicial y final de la aplicación del CIMA.

A continuación se muestran, a modo de ejemplo, algunas de las escaleras generadas.

Como se puede comprobar en las siguientes (correspondientes a los contenidos 1 y 2 del cuadro de niveles), tras la aplicación del CIMA la evolución de los alumnos hacia modelos mentales más complejos y completos es evidente, disminuyendo la cantidad de estudiantes que se encontraban en el nivel más bajo y aumentando los del nivel más alto.

1. Control de la luz

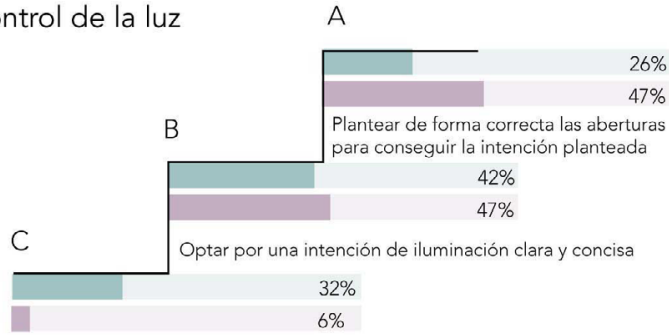

2. Legibilidad de la A intención espacial

A

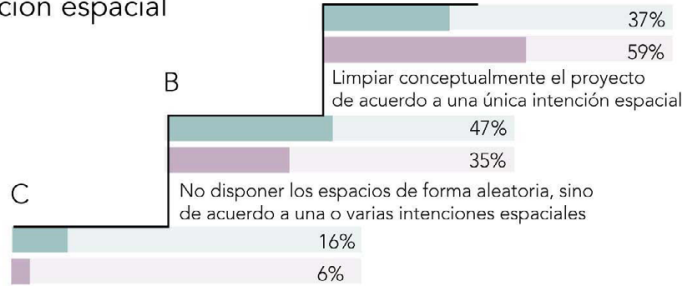

Figura 4. Algunas de las escaleras de Aprendizaje de contenidos relacionados con el proyecto. Contenidos 1 y 2 de la tabla 2

Ciclos de Mejora en el Aula (2020). Experiencias de Innovación Docente de la US Esta obra se distribuye con la licencia Creative Commons 
No obstante, la progresión ascendente no se da en todos los contenidos debido a que el ejercicio evaluado tras el CIMA era de un nivel de complejidad superior al anterior, lo que se ha traducido en que hay más alumnos que han realizado un retroceso, pues no han sido capaces de trabajar correctamente ese contenido con el incremento de dificultad que implicaba. Esto sucede especialmente en los contenidos relacionados con la expresión gráfica. En la figura 5 que se muestra a continuación, podemos ver que el contenido 9 (planos) no ha tenido una progresión ascendente. En este caso concreto se traduciría en que las nuevas complejidades que suponía el ejercicio no han sabido trasladarse al dibujo de los planos, mientras que en el ejercicio anteriormemente evaluado, más sencillo, una mayor cantidad de alumnos era capaz de superar el obstáculo.

Aunque sea algo comprensible, se deberá tener en cuenta en el diseño de futuros CIMAs, incidiendo más en el trabajo de estos contenidos.

9. Planos

A

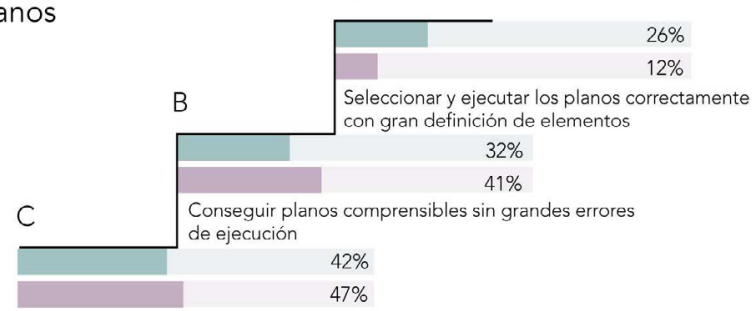

10. Maqueta

A

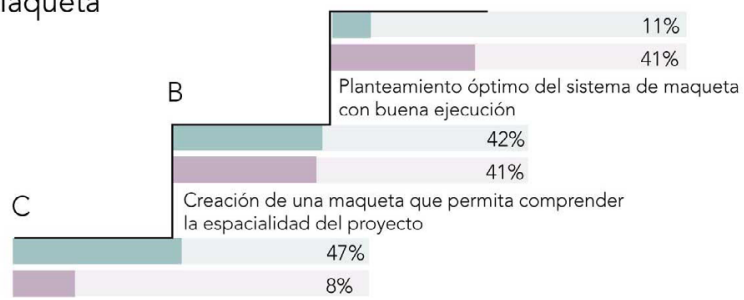

Figura 5. Algunas de las escaleras de Aprendizaje de contenidos relacionados con la expresión gráfica del proyecto

Ciclos de Mejora en el Aula (2020). Experiencias de Innovación Docente de la US Esta obra se distribuye con la licencia Creative Commons 


\section{Evaluación del CIMA}

\section{Cuestiones a mantener y cambios a introducir en un futuro CIMA o en la práctica habitual}

La valoración de la aplicación del CIMA resulta positiva, puesto que se ha conseguido dar forma a una asignatura que aunque partiera de un modelo que ya superaba al tradicional, en ocasiones pecaba de ingenuo o improvisado. Aplicar el CIMA ha permitido experimentar actividades que incorporaré a mi docencia habitual, como el de las referencias salpicadas o el de las críticas basadas en preguntas abiertas.

La actividad que ha supuesto una mayor innovación con respecto a mi modelo didáctico habitual han sido las críticas cruzadas, que también considero más eficaz puesto que trabaja de una forma completa los contenidos esenciales de la asignatura, incidiendo de una forma muy precisa en el criterio principal del CIMA, conforme al cuál las actividades se basarán en el principio de autonomía. Trataré, por tanto, de incorporarla en mi docencia futura, aunque no como un actividad puntual sino como un recurso estructural al que recurrir de forma repetida y continuada. También creo que este tipo de actividades deberían trabajarse como un entrenamiento en clase, con la perspectiva de la maduración a largo plazo.

Por otra parte, una mejora que introduciría claramente sería la de agrupar los proyectos por grupos de aproximación similar para realizar críticas conjuntas, con el fin de ahorrar tiempo y evitar repetir conceptos.

Por último, en cuanto a las actividades del arquitecto/a y lectura de la semana hay que aclarar que realmente no se han incorporado en el CIMA, sino que se vienen trabajando desde principio de curso. Creo que esta iniciativa es bastante positiva, porque trabaja el valor de la autonomía y da

Ciclos de Mejora en el Aula (2020). Experiencias de Innovación Docente de la US Esta obra se distribuye con la licencia Creative Commons 
claves para el trabajo con referencias en casa. No obstante, la actividad me parece excesivamente libre y realmente no existe un registro durante el curso de si los alumnos la están llevando a cabo (correctamente) o no. Además, las lecturas en ocasiones son complejas y puede que no estén siendo bien comprendidas.

Estos aspectos no se trabajan de forma específica en clase por falta de tiempo, ya que se da más importancia a las correcciones, lo que impide un mayor aprovechamiento de sus posibilidades. No obstante pienso que agrupando las correcciones quedaría tiempo para abordar estas cuestiones a través de actividades de puesta en común, exposiciones cortas, debates, análisis guiados por grupos, etc., que trataré de introducir en un futuro CIMA para dar más valor a estas actividades que pueden llegar a ser claves en el proceso de aprendizaje.

\section{Principios didácticos}

- Reconocer al alumno el papel activo en el proceso de aprendizaje, que debe realizarse de forma autónoma. El papel del profesor es el de diseñar la estrategia y guiar y acompañar al alumno en ese proceso.

- Realizar siempre diagnósticos para conocer los modelos mentales de los estudiantes y detectar las principales dificultades en el aprendizaje.

- Diseñar el modelo de conocimiento como un proceso de acupuntura: actividades estratégicas que activan contenidos específicos.

- Emplear un modelo metodológico basado en: (momento 1) ideas de los estudiantes (momento 2) actividad de contraste; aportando información sólo cuando se considere que el alumno ha llegado al límite al que podría llegar por sí mismo.

Ciclos de Mejora en el Aula (2020). Experiencias de Innovación Docente de la US Esta obra se distribuye con la licencia Creative Commons 
- Motivar a los estudiantes dando siempre un valor al trabajo realizado a través de incentivos en la calificación.

- Puntuar en función de la evaluación de modelos mentales o niveles de progresión en el aprendizaje alcanzados, teniendo en cuenta todos los contenidos.

- Considerar una evaluación continua "reversible" en la que se pueden modificar las calificaciones en función del modelo mental alcanzado al final del curso, entendiendo que cada persona tiene sus propios tiempos y ritmos para ascender en la escalera.

- Evaluar mi propia enseñanza.

Ciclos de Mejora en el Aula (2020). Experiencias de Innovación Docente de la US Esta obra se distribuye con la licencia Creative Commons 
Palabras clave: Proyectos I, Grado en Fundamentos de la Arquitectura, Docencia Universitaria, Experimentación Docente Universitaria, Autoaprendizaje Guiado

Keywords: Design I, Fundamentals of Architecture Degree, University Teaching, University Teaching Experimentation, Guided self-learning

\section{Referencias bibliográficas}

Bain, K. (2006). Lo que hacen los mejores profesores universitarios. Valencia: Publicaciones Universidad de Valencia.

Finkel, D. (2008). Dar clase con la boca cerrada. Valencia: Publicaciones Universidad de Valencia.

Porlán, R. (2017). Enseñanza Universitaria. Cómo mejorarla. Madrid: Editorial Morata.

Ciclos de Mejora en el Aula (2020). Experiencias de Innovación Docente de la US Esta obra se distribuye con la licencia Creative Commons 